\title{
Di-(2-ethylhexyl) phthalate is metabolised by primary human thyroid cells and may influence thyroglobulin secretion
}

Juliana Frohnert Hansen¹, Marianne Møller Brorson¹, Marie-Louise Hartoft-Nielsen¹, Malene Boas² , Katharina M. Main², Hanne Frederiksen² Jacob Hofman-Bang ${ }^{1}$, Åse Krogh Rasmussen ${ }^{1}$, Ulla Feldt-Rasmussen ${ }^{1}$

Department of Medical Endocrinology, PE 2132, Rigshospitalet, University of Copenhagen, Denmark

2 Department of Growth and Reproduction, Rigshospitalet, University of Copenhagen, Denmark

\section{Introduction}

Di-(2-ethylhexyl) phthalate (DEHP) is an endocrine disrupting chemical (EDC), used by the industry mainly as a plasticizer, but also as an additive in many different consumer products'. DEHP and other phthalates are suspected to influence the thyroid axis. Epidemiological studies suggest a negative correlation between phthalates and blood concentration of peripheral thyroid hormones, but few experimental studies and mainly animal studies have investigated this ${ }^{2}$. Hence, the aim of our study was to investigate if primary human thyroid cell cultures were able to metabolise DEHP, and if DEHP influenced thyroglobulin ( $\mathrm{Tg})$ secretion and Tg-mRNA expression in these cells.

\section{Methods}

Human thyrocytes, obtained from thyroidectomies, were cultured to confluent monolayers. These were exposed to DEHP in concentrations $10^{-9}$ to $10^{-4} \mathrm{M}$ for 24,48 or $72 \mathrm{~h}$ in the presence of thyroid stimulating hormone (TSH) (1 IU/I). Tg-secretion and DEHP metabolites were quantified in the cell supernatants (ELISA and liquid chromatography-
Tandem mass spectrometry, respectively), and Tg-mRNA expression was analysed in the cells by RT-qPCR. Results are shown as mean SD and statistical analyses performed using two-way ANOVA (SASinstitute).

\section{Results}

Cell cultures metabolised DEHP $\left(10^{-7}-10^{-4} \mathrm{M}\right)$ to its primary metabolite mono-ethylhexyl-phthalate (MEHP). No secondary DEHP-metabolites were detected. The MEHP contents in cell cultures with low DEHPconcentrations added $\left(10^{-8}\right.$ and $\left.10^{-9} \mathrm{M}\right)$ were lower than the detection limit of the method used and are therefore not displayed here.

A concentration dependent increase of MEHP was observed with increasing DEHP added to cell cultures (exposure time: $72 \mathrm{~h}$ ). However, an inverse relationship was observed when looking at the relative metabolism:

$$
\text { Relative metabolism: } \frac{\text { observed MEHP content }}{\text { maximal possible MEHP content }} \times 100 \%
$$

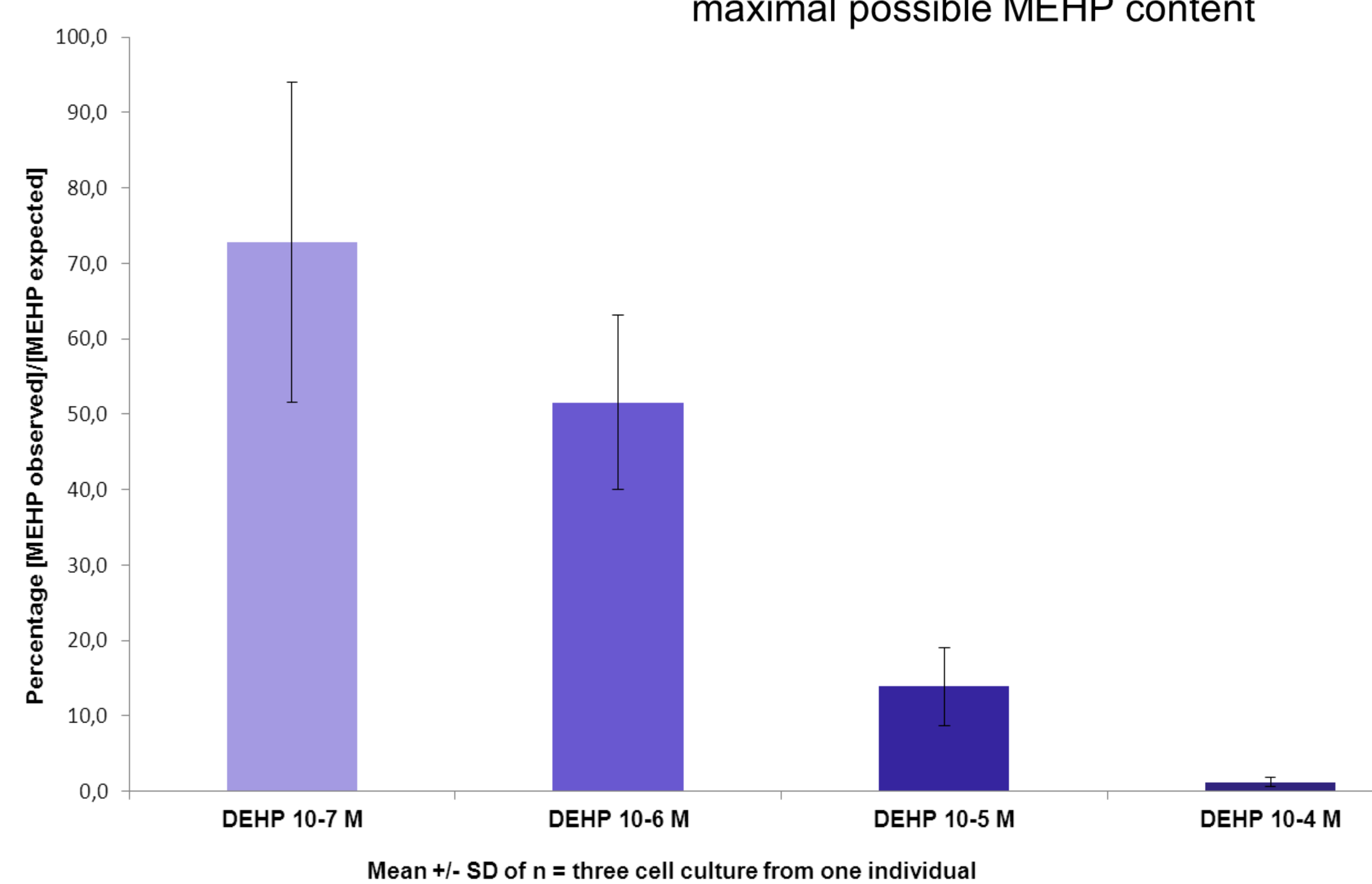

Fig. 1: Relative DEHP metabolism after $72 \mathrm{~h}$ exposure. Less DEHP is metabolised with increasing concentrations when comparing to the maximal metabolism (i.e. the MEHP concentration if all DEHP was metabolised).

To investigate the kinetics of DEHP-metabolism, a time study was conducted. The MEHP-content was assessed after $0,1 / 4,1 / 2,1,2,4,24,48$ and $72 \mathrm{~h}$ of DEHP-exposure $\left(10^{-7} \mathrm{M}\right)$. The majority of DEHP was metabolised during the first $\mathbf{2 4}$ hours, where after the conversion rate decreased.

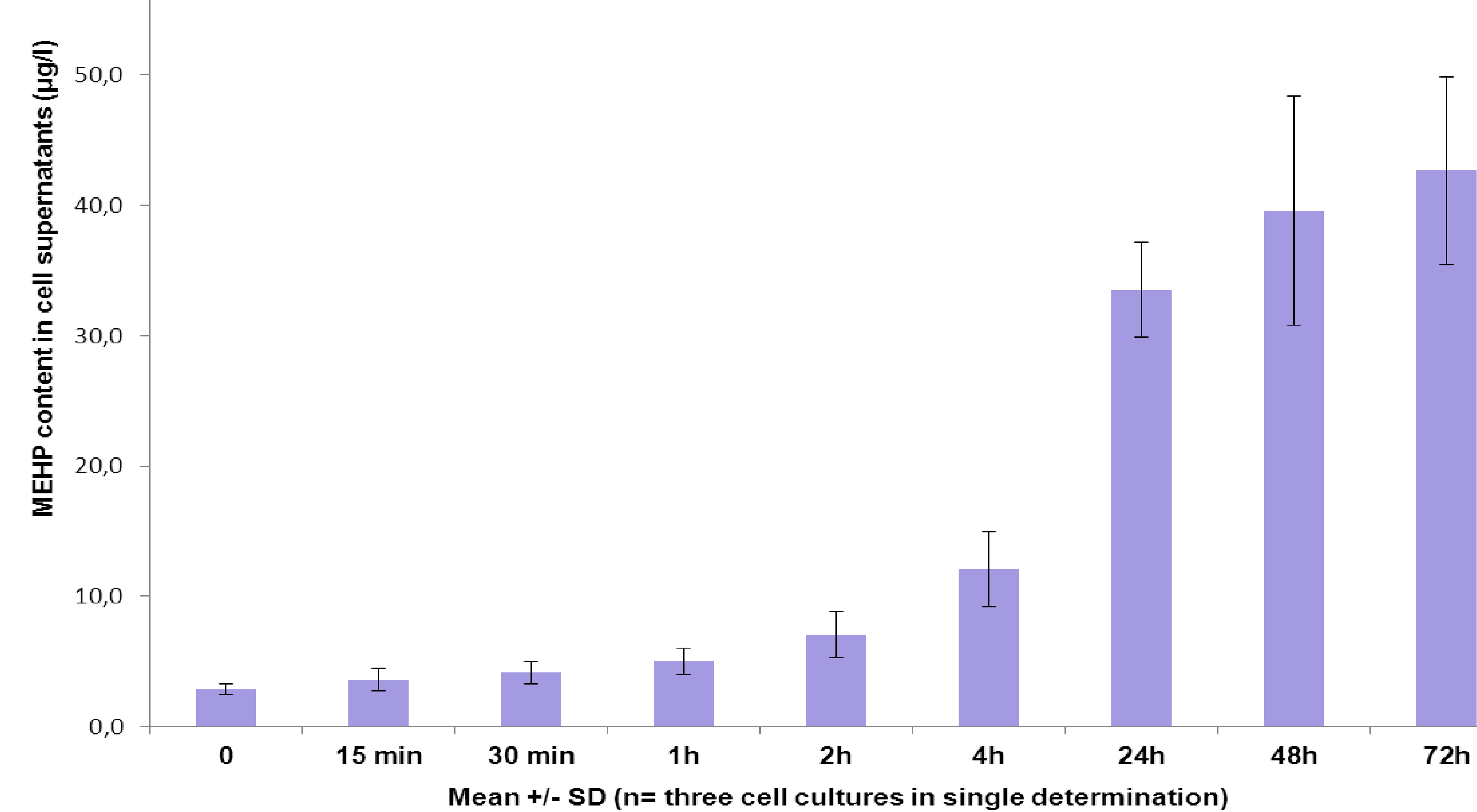

Fig. 2: Kinetics of DEHP-metabolism measured as the MEHP content in cell supernatants at 9 time points after addition of DEHP.
The Tg-secretion of primary thyroid cell cultures was unaffected after $72 \mathrm{~h}$ DEHP exposure $\left(10^{-9}-10^{-4} \mathrm{M}\right)(\mathrm{p}=0.86, \mathrm{n}=$ five cell cultures in single determination). Since a pilot study suggested an influence by DEHP to occur earlier, a time study was conducted, analysing Tg-secretion and Tg-mRNA expression after 24, 48 and $72 \mathrm{~h}$ of DEHP exposure (DEHP 10${ }^{9}-10^{-5} M, n=$ three cultures in single determination). Though an inhibition of $\mathrm{Tg}$-secretion was suggested after $48 \mathrm{~h}(\mathrm{p}=0.04)$, this was not confirmed by Tg-mRNA ( $\mathrm{p}=\mathbf{0 . 3 7}$ ). Neither Tg-secretion nor Tg-mRNA expression assessed after 24 and $72 \mathrm{~h}$ seemed to be influenced by DEHP (Tg/Tg-mRNA $24 \mathrm{~h}: \mathrm{p}=0.37 / 0.48 ; \mathrm{Tg} / \mathrm{Tg}-\mathrm{mRNA} 72 \mathrm{~h}$ : $\mathrm{p}=0.10 / 0.18$ ).

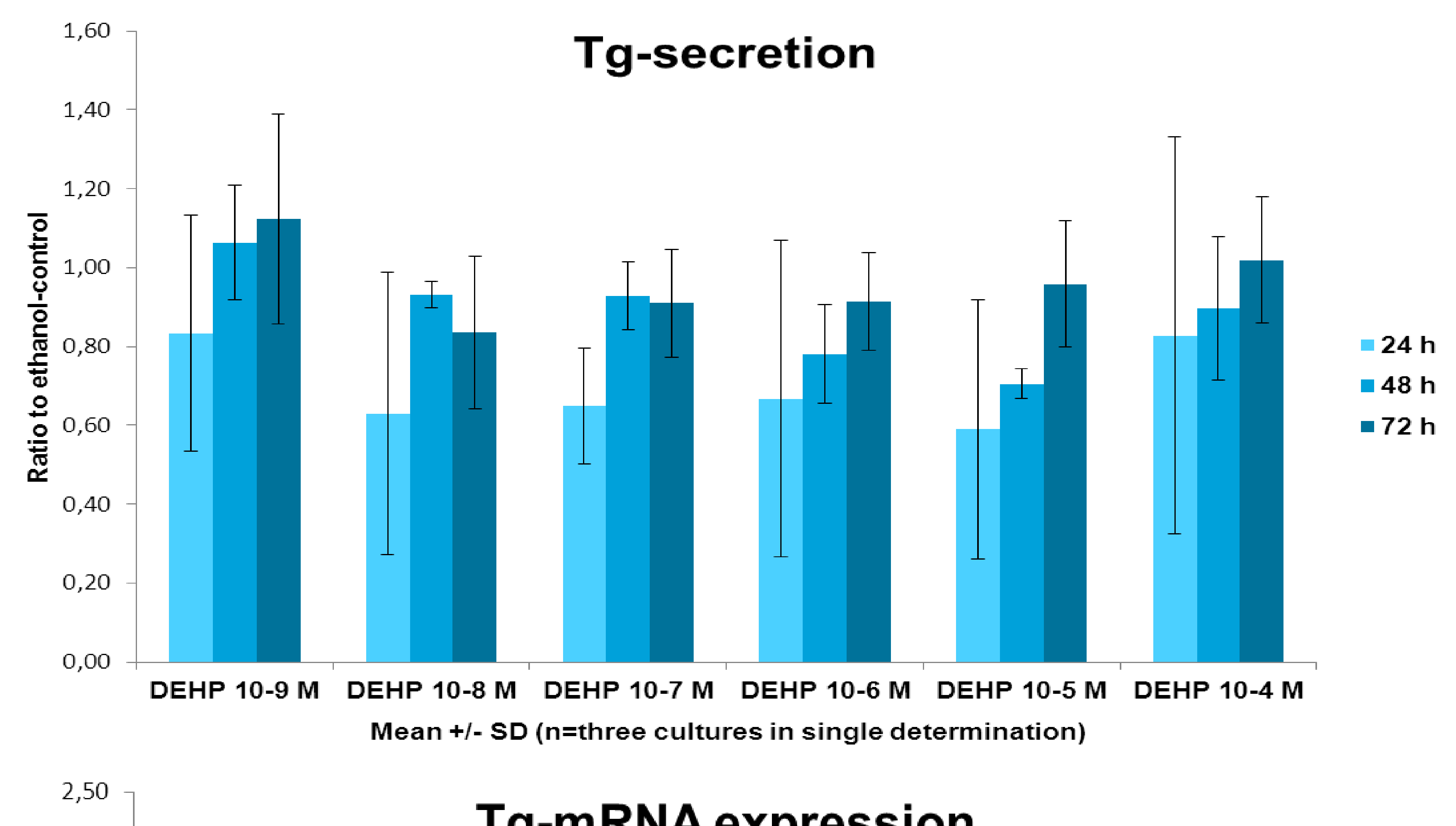

Tg-mRNA expression

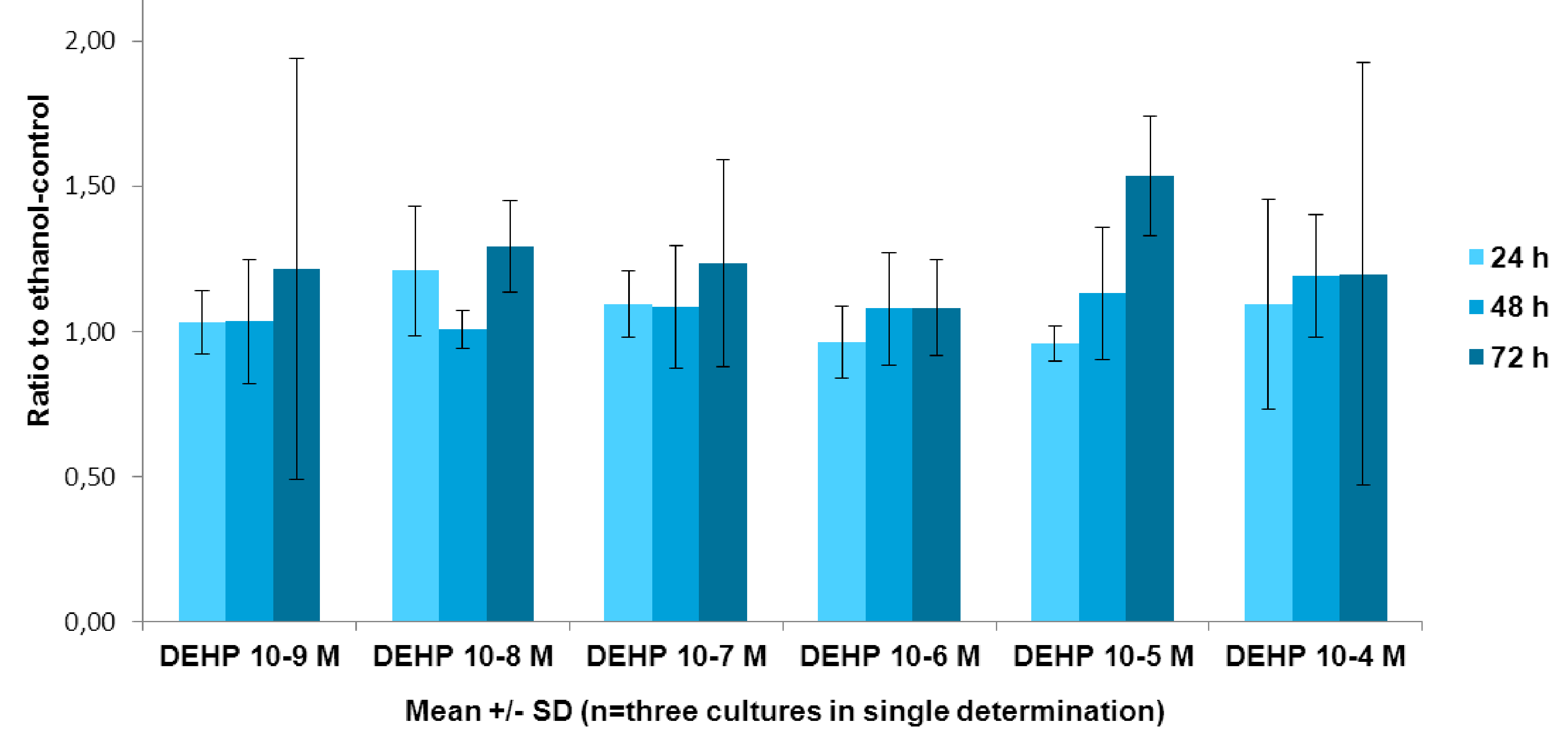

Fig. 3: Tg secretion and Tg-mRNA expression. Post-hoc analysis (Tuckey) of $48 \mathrm{~h}$ exposure (upper panel): only $10^{-9} \mathrm{M}$ had higher $\mathrm{Tg}$-concentrations compared to $10^{-5} \mathrm{M}, \mathrm{p}=0.04$.

However, the intra-culture variation of $\mathrm{Tg}$ and $\mathrm{Tg}$ mRNA results, may disguise a concentration dependent effect. In addition, working with phthalates is complex. At high concentrations, the phthalates did not seem completely solubilised, and phthalate content in experiment wells were modified by phthalate transfer from neighbouring wells and applied plastic materials (data not shown). Hence, demonstrating a concentration dependent phthalate effect in cell cultures is challenging and necessitates a deeper insight in phthalate handling.

\section{Conclusion}

DEHP is internalised and metabolised by primary human thyroid cell cultures, a rapid process occurring mainly during the first 24 hours of exposure. The relative conversion, however, decreased inversely proportional to the DEHP concentration added, indicating an active saturable process in the thyroid cells. We were not able to detect any significant concentration-dependent effect of DEHP on Tg secretion or mRNA expression. Nevertheless, substantial intra-culture variation of
$\mathrm{Tg}$ and $\mathrm{Tg}$-mRNA production in primary human thyroid cell cultures as well as challenging phthalate handling complicates the demonstration of a concentration dependent phthalate effect, and further knowledge about phthalate handling is a prerequisite in performance of future studies.

${ }^{1}$ European Union Risk Assessment Report (2008), Bis (2-ethylhexyl) phthalate. 2nd Priority List, Volume 80.

${ }^{2}$ Boas M, Feldt-Rasmussen U, Main KM (2012) Thyroid effects of endocrine disrupting chemicals. Mol Cell Endocint -Rasmussen U, Main KM (2012) Thyroid effects of endocrine disrupting chemicals. Mol Cell Endocrinol 